physical health, both clinically and after laboratory and other investigations, and were referred only because of behavioural problems associated with their appearance. Moreover, someone with a two-year history of arthralgia is hardly in good health.

R THOMPSON Regional Department of Immunology, East Birmingham Hospital, mingham Thompson, R A, and White, R H R, Lancet, 1973, 2,

\section{Otitis media}

SIR,-In his article on otitis media (21 February, p 443) Mr J F Birrell, writing of glue ear, states that "unlike acute otitis media, in which wax never obscures the membrane, cerumen may fill the external meatus." should like to ask Mr Birrell (whose article I found most enlightening) whether this really means that patients with acute otitis media never have a waxy obstruction.

Could the converse also be true, that if a patient complains of pain in the ear and a waxy obstruction is found there cannot be underlying otitis media? In addition, if such an inflammation is possible is it safe to syring such an ear before the pain has subsided?

C SALKIN

Rochdale

** We showed this letter to Mr Birrell, whose reply is printed below.-ED, $B M \mathcal{H F}$

SIR,-In reply to Dr Salkin's queries, I have never seen a case of acute otitis media in child in which the tympanic membrane was obscured by wax. If a child complains of pain in the ear and if this is real pain which is unlikely to be caused even by hard wax should look for another cause-for example, carious teeth. I would not advocate syringing the ear before the pain has subsided.

\section{J F BIRRELI}

Royal Hospital for Sick Children, Edinburgh

Detection of somatic muscle fasciculation on electrocardiograms

SIR,-The article by Drs D J Thomas and D O Williams (6 March, p 557) contains the information that fasciculation potentials can be recorded through plate electrodes on the limbs during routine electrocardiography. This information is not new to neurologists. The superiority of large surface electrodes over needle electrodes for the detection of fasciculation in neuromuscular disorders is well recognised and forms the basis of a standard diagnostic procedure. ${ }^{12}$ It is, perhaps, rathe surprising that the authors should have made no reference to this

The authors make the point that it is possible to eliminate motor unit activity from an ECG record by the use of a high-frequency filter. The additional point should be made that the frequency range of most commercial ECG machines is not, in any case, adequate to record any but the largest fasciculation poten- tials. An ECG recorder should not, therefore, be used instead of an electromyographic polygraph for the detection of fasciculation.

Finally, fig 1 appears to show "contraction fasciculations.", 3 The diagnostic significance of these is quite different from that of spontaneous isolated fasciculations and this important distinction has been ignored by the authors

\section{University Department of Clinical Neurology, ational Hospital Queen Square,}

Hjorth, R J, Walsh, J C, and Willison, R G, fournal of Neurological Sciences, 1973, 18, 469. Willison, $\mathrm{R}$ G, in Studies on Neuromuscular Diseases,
ed K Kunze and J E Desmed, p 108. Basel, Karger,
1973 .

Denny-B 61, 311 .

R W GILLIAT R G WILLISON

\section{Domiciliary oxygen in advanced chronic} bronchitis

SIR,-Your leading article (28 February, p 484) stresses once again the importance of pulmonary hypertension to morbidity and mortality in hypoxaemia associated with chronic bronchitis. Pulmonary hypertension, we feel, is of only minor importance and only one casualty of the most important featuresevere arterial hypoxia. Pulmonary artery pressure is only modestly elevated during most of the natural history ${ }^{1}$ and levels are certainly lower than those sustained for many years in pulmonary embolic disease and rheumatic heart disease. Furthermore, congestive cardiac failure is not the appropriate term for a "congestive syndrome" in which the heart's action is not seriously imperilled.

The object of treatment in this disease is the hypoxaemia. The selection of suitable patients for long-term domiciliary treatment will certainly pose problems, and indicators of therapeutic response are required. Pulmonary hypertension might be one such indicator, but it is to be hoped that a more readily measured parameter will be found. Red cell mass looks a good runner. We reiterate, pulmonary hypertension leading to pressure overload of the right ventricle is not in our opinion an adequate explanation of the nature of this disorder.

P B ANDERSON

S R BRENNAN P HOWARD

Department of Medicine, Royal Hospital,

' Anderson, P B, et al, Quarterly fournal of Medicine, $1973,167,563$.

\section{Carcinoembryonic antigen and mucus}

SIR,-Carcinoembryonic antigen (CEA) was once thought to be specific to human malignan and fetal alimentary mucosa. ${ }^{1}$ Much doubt has been thrown on this concept by the finding of CEA in many normal human secretions, in particular faeces, ${ }^{2}$ meconium, ${ }^{3}$ urine, ${ }^{4}$ cervical mucus, ${ }^{5}$ and saliva ${ }^{6}$ as well as the fluid from benign breast cysts. $^{7}$ We now report its presence in normal human nasal mucus, confirming the belief of Rogalsky ${ }^{8}$ that CEA is a component of all normal mucous secretions.

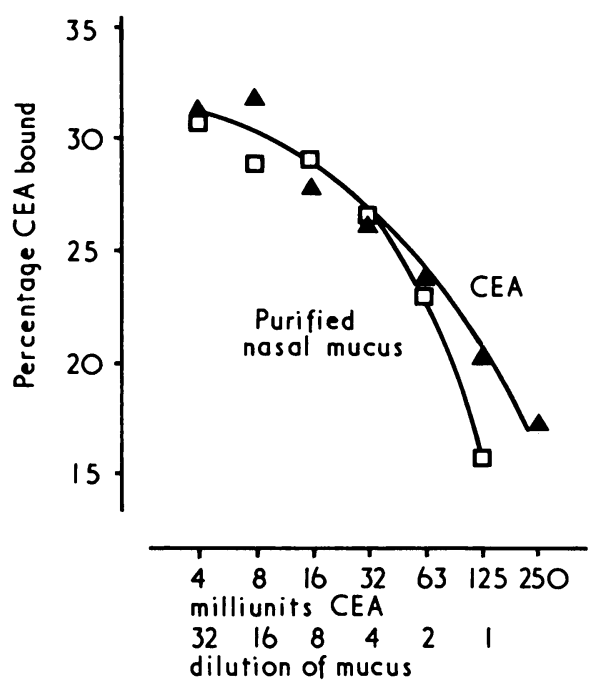

Normal human nasal mucus was obtained from five volunteers by nasal washing with $0.9 \%$ saline. The washings were pooled, clarified by centrifugation, and extracted into $1.0 \mathrm{M}$ perchloric acid to obtain the CEA-containing fraction. ${ }^{9}$ This was further purified by gel filtration on Sephadex G-200. ${ }^{9}$ The efficiency at inhibiting the binding of ${ }^{125} \mathrm{I}$-labelled CEA to anti-CEA serum was assessed, relative to "pure" unlabelled CEA, by serially diluting the materials. The results (see figure) show that the fraction from nasal mucus inhibits binding as efficiently as CEA itself and is therefore immunologically identical with it (as referred to the particular anti-CEA serum used). Blood-group glycolipids $A, B$, and $H$, tested in the same manner on the same occasion, failed significantly to inhibit binding even when present in 10000 -fold excess (w/w)

CEA has in recent years been defined ${ }^{10}$ as any antigen which is immunologically identical with the original Montreal preparation. The definition makes no reference to the particular antiserum used in testing and is therefore different from the definition of Gold and Freedman, ${ }^{1}$ who identified CEA simply by testing tissue extracts with their own, specified, antisera. These two definitions are capable of describing different antigenic determinants, as is witnessed by the varying degrees of cancer specificity reported for the "CEA test" by different authors. ${ }^{11} 12$

If the confusion is to be resolved we require not an international standard preparation of antigen (National Institute for Biological Standards and Control, Holly Hill, London), but a standard antiserum which would conform to the specificity reported for the original sera of Gold and Freedman. ${ }^{1}$ CEA itself may then be defined as any material which reacts with that.

DAVID FREED

GEOFFREY TAYLOR

University Department of Bacteriology

and Virology,

1 Gold, P, and Freedman, S O, fournal of Experimental

Medicine, 1965, 122, 467. Fournal of Experimental

Freed, D L J,

Goldenberg, D M, et al, American fournal of Obstetrics and Gynecology, $1972,113,66$.

4 Nery, R, et al, British fournal of Cancer, 1974, 29, 413

5 Hall, R R, et al, British Medical fournal, 1972, 3, 609 Martin, F, and Devant, J, fournal of the National Cancer Institute, 1973, 50, 1375

Fleisher, M, et al, Clinical Chemistry, 1974, 20, 41.

Rogalsky, V Y, Lancet, 1974, 2, 729.

Krupey, J, Gold, P, and Freedman, S O, fournal of

10 Terry, W D, et al, Transplantation Reviews, 1974, 20, 100

1 Thomson, D M P, et al, Proceedings of the National Academy of Sciences of the USA, 1969, 64, 161 .

Freed, D L J, in Topics in Gastroenterology I, ed S C Truelove and D P Jewell. Oxford, Blackwell, 1973. 